\title{
Repetitive construction processes scheduling using mixed-integer linear programming
}

\author{
Piotr Jaśkowski \\ Katedra Inżynierii Procesów Budowlanych, Wydział Budownictwa i Architektury, Politechnika \\ Lubelska,e-mail: p.jaskowski@pollub.pl
}

\begin{abstract}
Many construction projects contain several identical or similar units, such as floors in multistory buildings, houses in housing developments, sections of pipelines or highways. Repetitive processes arise from the subdivision of a generalized construction process into specific activities associated with particular units. In many cases it is possible to perform individual processes (repeated in each units) in alternative ways (modes). Regardless of the construction project procurement system, duration and cost are the key factors determining project's economic efficiency and fulfillment of the owner's needs and requirements. Minimizing project duration and cost are the most important criteria for schedule optimization. Processes that repeat from unit to unit are realized by specialized crews. Uninterrupted resource utilization becomes an extremely important issue for scheduling repetitive processes to minimize employment costs. In this paper, the problem of selecting appropriate modes and minimizing the total project cost and with a constraint on project duration is presented with respect to the continuity of the crews' work. The paper uses the mixed integer linear programming to model this problem and uses a case study to illustrate it.
\end{abstract}

Keywords: construction project, project scheduling, repetitive processes, time-cost optimization, work continuity constraints.

\section{Introduction}

Repetitive construction projects are projects with activities that are repeated in similar or identical units. Typical examples of repetitive projects are: construction of high-rise buildings (repeatable floors with the same works to be conducted in each of them), finishing works in typical floors or in apartment complex etc. For this kind of processes, the construction crew is required to repeat the same operations in a defined number of units (floors, houses, apartments, etc.). As repetitive projects represent a large portion of the construction industry, it is important to develop efficient scheduling methods of this type of projects.

The Critical Path Method (CPM), probably the most popular planning and scheduling method, does not suit the needs of repetitive projects: it does not facilitate handling large numbers of repetitive activities and modeling continuity constraints. Several alternative approaches have been developed over the recent decades to cope with the requirements of construction projects either composed of repetitive activities or have a linear development. A variety of approaches were developed, for instance, the Line of Balance (LOB), Construction Planning Technique (CPT), Vertical Production Method (VPM), TimeLocation Matrix Model, Time Space Scheduling Method, Disturbance Scheduling, Horizontal and Vertical Logic Scheduling for Multistory Projects (HVLS), and Repetitive Project Model (RPM). 
However, in the literature on the subject, there are few records of attempts to allow for the whole set of requirements and constraints of repetitive projects, such as optimization of the total project duration with respect to efficient resource usage and assuring continuity of work. Ammar [2] integrated CPM and LOB model to schedule repetitive projects in an easy non-graphical way considering both logic dependency and resource continuity constraints. Overlapping activities of a single typical unit are used to model duration and logical relationships of repetitive activities. The integrated CPM-LOB model allows the user to minimize the total duration of repetitive projects with uninterrupted usage of resources. Kang et al. [8] developed an optimization model about repetitive project scheduling with resource use efficiency. Khailed and Khaled [9] designed a multi-objective optimization model based on a genetic algorithm, which helped planners to reduce duration of the project and improve work continuity. Alexandros and Sergios [1] pointed out that the critical path determined by LSM was different than its counterpart defined by means of CPM network diagram with resource continuity constraints, and the critical path determined by CPM compromised resource continuity in search of optimal total duration. Wang et al. [10] analyzed the optimization of total duration with resource constraint and resource share. Fan et al. [4] presented a genetic-algorithm-based cost minimization model for repetitive projects that allowed for soft logic and changing sequence of units.

The repetitive construction projects scheduling problem involves three conflicting objectives: minimizing project duration, project total cost, and project total interruption time (El-Kholy [3]). Several models were developed for time-cost trade-off. They were aimed at finding optimum crew formation and optimum output rate. Hegazy and Wassef [5] developed a model to minimize total construction cost (the sum of direct cost, indirect cost, interruption cost, as well as incentives and liquidated damages), integrating LOB and CPM methodology. Their model enabled performing time-cost trade-off analysis considering a specified deadline and alternative construction methods with associated time, cost, and crew options. Hyari and El-Rayes [6] constructed a multi objective optimization model based on a genetic algorithm. This model helps planners to evaluate optimum plans by minimizing project duration and maximizing work continuity at the same time. Ipsilandis [7] presented a multi objective linear programming model for scheduling linear repetitive projects, which considers cost elements regarding the project's duration, the idle time of resources, and the delivery time of the project's units.

In many practical projects in construction it is possible to perform individual activities in alternative ways (modes). In addition to changing the crew formation modes, also the substitution of construction methods or materials can by profitable for contractor and owner. The modes differ in processing time, lags between activities, and resource requirements, so they affect the project's outcomes. Therefore, project scheduling problems with multi technological modes aims at finding the optimal order of activities, the start times of each activity, and the execution modes for all activities in a project while verifying a set of precedence and resource constraints.

This paper is aimed at modeling a repetitive project scheduling problem under the following assumptions:

1. A single project consists of a number of succeeding activities with several execution modes. The activities are executed by specialized crews moving from unit to unit. The sequence of activities and units is determined and unchangeable.

2. Each crew can start their work in a succeeding unit after completion of their activities in the current unit. The start time of each activity in each unit is also dependent upon the completion of preceding activities in this unit (precedence constraints of activities must hold). 
3. Activities cannot be interrupted.

4. Each activity must be performed in one mode common to all units. Switching modes of the same activity from unit to unit is not allowed.

5. The objectives are to minimize the project cost under project duration limit with respect to the continuity of the crews' work.

\section{Problem formulation}

In each of the $j$ units the project was divided into $(j \in J, J=\{1,2, \ldots, m\})$, there are processes $i$ to be conducted by crews assigned specifically to them $(i \in I, I=\{1,2, \ldots, n\})$. Thus, $(i, j)$ means process $i$ conducted in unit $j$. The sequence of processes of all kinds to be conducted in a unit is defined by a graph $G=\langle I, A\rangle$ directed, with one initial node and one final node, where $I$ is the set of nodes (identical with the set of process types), and $A=I \times I$ is the set of arches connecting the nodes and representing relationships between processes. The sequence of processes is the same for each unit. The sequence of units is fixed and in accordance with their numbering.

For each process type, $i$, a set $W_{i}$ of technological modes can be defined. Selection of the mode to be applied is modeled by means of a binary $x_{i, w} \in\{0,1\}$. This variable, $x_{i, w}$, equals 1 if the process $i$ is to be executed in the mode $w \in W_{i}$, otherwise $x_{i, w}$ equals 0 .

To provide input for the analysis, the time $t_{i, j, w}$ and cost $k_{i, j, w}$ of conducting a process $i$ in unit $j$ in the mode $w \in W_{i}$ need to be assessed separately - on the basis of data on crews' productivity, quantities of work, process-specific resource consumption rates and resource prices. The decision variable representing the time of work in unit $j$ conducted by the crew $i$ is $t_{i, j}$.

Optimal set of modes and start times $s_{i, j}$ of processes $(i, j)$ with the constraint of allowable project duration not exceeding the deadline, $T$, can be obtained by solving the following basic mixed integer linear program:

$$
\begin{aligned}
& \min z: \quad z=\sum_{i \in I} \sum_{j \in J} \sum_{w \in W_{i}} k_{i, j, w} \cdot x_{i, w}+\rho \cdot \sum_{i \in I}\left(s_{i, m}-s_{i, 1}-\sum_{j=1}^{m-1} t_{i, j}\right), \\
& s_{1,1}=0, \\
& t_{i, j}=\sum_{w \in W_{i}} t_{i, j, w} \cdot x_{i, w}, \forall i \in I, \forall j \in J, \\
& s_{n, m}+t_{n, m} \leq T, \\
& s_{b, j} \geq s_{a, j}+t_{a, j}, \forall(a, b) \in A, \forall j \in J, \\
& s_{i . j+1} \geq s_{i, j}+t_{i, j}, \forall i \in I, \forall j=1,2, \ldots, m-1, \\
& \sum_{w \in W_{i}} x_{i, w}=1, \forall i \in I, \\
& x_{i, w} \in\{0,1\}, \forall i \in I, \forall w \in W_{i}, \\
& s_{i, j} \geq 0, \forall i \in I, \forall j \in J,
\end{aligned}
$$

where $\rho$ is a sufficiently small number. 
The objective function (1) minimizes the total project cost together with the total idle time of the crews - at the optimally selected execution modes and within allowed duration. For each process, the crew's idle time is calculated as a difference between:

- the scheduled period of a particular process being underway reduced by the duration of this process in the last unit - established as the time span between the start date of the process in the last unit and the start of this process in the first unit,

- and the sum of times of conducting the works in particular units.

The project starts at the moment $s_{1,1}=0$, so as the first process is initiated in the first unit (2). Equation (3) defines the time of conducting a process in a particular unit. The project must be completed no later than the deadline, which is described by relationship (4). Starting dates of processes other than the first one are defined by means of relationships (5) and (6) - considering the sequence defined by the graph $G$ and those related with the sequence of units. For each process, only one execution mode can be selected, which is described by condition (7). The variables must fulfill boundary conditions (8) and (9).

The above model should be supplemented with additional conditions that result from construction methods, such as lags due to concrete hardening or insulation drying times. These may differ depending on modes. For instance, if traditional plaster would be selected, there should be a lag for the render to set and dry before it can be painted; if the wall finished by drylining, painting may start practically immediately.

If a process $p$ can be conducted in mode $s$ that requires a lag before a succeeding process $r$ may start, and the duration of the lag is $t_{p}^{t}$, so the starting dates of this succeeding process can be calculated according to formula (10) - a modified version of formula (5):

$$
s_{r, j} \geq s_{p, j}+t_{p, j}+t_{p}^{t} \cdot x_{p, s}, \forall j \in J
$$

Selection of particular modes may imply that the processes to follow are conducted by a certain mode. For instance, masonry partition walls can be finished with wet plaster or dry lined, whereas drywall partitions will only need to be skimmed and primed.

Let's assume that, for a process $u$, there is a choice between modes $c$ and $d$ that imply, consecutively, selection of modes $e$ or $f$ of the succeeding process $v$. Therefore, the variables representing these decisions are to fulfill the following condition:

$$
x_{u, c}+x_{u, d}=x_{v, e}+x_{v, f} .
$$

\section{Example}

To prove the validity of the model, it was applied to scheduling the finishing works for a new-built apartment block. It was assumed that there were ten units (apartments) and five processes: erection of partition walls, plastering, laying floor screeds, wall painting and floor covering. The processes were to be executed in sequence, as listed. Additionally, sequence-related relationships were introduced between plastering and painting and between laying screeds and floor covering to enable introducing lags required by certain modes. Following modes were considered:

- Partition walls made of 1) light concrete blocks with a traditional mortar, 2) gypsum blocks laid in a thin-layered adhesive, 3) precision ceramic hollow blocks joined by adhesive (the wall can be erected to its full height in one day and there is no lag before plastering).

- Plastering 1) traditional cement-lime plaster on walls and ceilings, 2) gypsum plaster of walls and ceilings, 3) skimming the partition walls and putting traditional 
cement-lime plaster on structural walls and ceilings; if modes 1) or 3) of erection of partition walls were chosen, this implies that only 1) or 2) plaster modes could be selected. If mode 2) of walls is picked, the only possibility of plastering is by mode 3).

- Screeds 1) monolithic screed on insulation (needs to harden and dry before floor covering), 2) dry prefabricated screed.

It was assumed that painting and floor covering come in one mode (decision of the client), and they are also excluded from cost analysis. Input on process durations and costs per particular unit and per mode are listed in Table 1.

Table 1. Example data

\begin{tabular}{|c|c|c|c|c|c|c|c|c|c|c|c|c|c|c|c|}
\hline \multirow{2}{*}{$i$} & \multirow{2}{*}{ Process } & \multirow{2}{*}{$\begin{array}{l}\text { Prede- } \\
\text { cessors }\end{array}$} & \multirow{2}{*}{$\begin{array}{c}\text { Mode } \\
\text { W }\end{array}$} & \multirow{2}{*}{$\begin{array}{c}t_{i}^{t} \\
\text { [days] }\end{array}$} & \multicolumn{10}{|c|}{ Process duration [days] on unit: } & \multirow{2}{*}{$\begin{array}{c}\text { Total cost } \\
{[€]}\end{array}$} \\
\hline & & & & & 1 & 2 & 3 & 4 & 5 & 6 & 7 & 8 & 9 & 10 & \\
\hline \multirow{3}{*}{1} & \multirow{3}{*}{$\begin{array}{l}\text { Partition } \\
\text { walls }\end{array}$} & \multirow{3}{*}{-} & 1 & 7 & 6 & 3 & 3 & 3 & 3 & 3 & 4 & 3 & 3 & 3 & 11770 \\
\hline & & & 2 & 7 & 8 & 3 & 4 & 4 & 3 & 4 & 5 & 3 & 4 & 4 & 18590 \\
\hline & & & 3 & 0 & 3 & 1 & 2 & 2 & 2 & 2 & 2 & 2 & 2 & 2 & 11500 \\
\hline \multirow{3}{*}{2} & \multirow{3}{*}{ Plastering } & \multirow{3}{*}{1} & 1 & 15 & 7 & 4 & 6 & 6 & 4 & 6 & 7 & 6 & 6 & 6 & 33900 \\
\hline & & & 2 & 15 & 6 & 4 & 4 & 5 & 4 & 5 & 6 & 5 & 4 & 4 & 15000 \\
\hline & & & 3 & 15 & 5 & 3 & 4 & 4 & 3 & 4 & 5 & 4 & 4 & 4 & 12300 \\
\hline \multirow{2}{*}{3} & \multirow{2}{*}{ Screeds } & \multirow{2}{*}{2} & 1 & 28 & 2 & 2 & 2 & 2 & 2 & 2 & 2 & 2 & 2 & 2 & 13950 \\
\hline & & & 2 & 0 & 1 & 1 & 1 & 1 & 1 & 1 & 1 & 1 & 1 & 1 & 17700 \\
\hline 4 & Painting & 2,3 & & - & 2 & 2 & 2 & 2 & 2 & 2 & 2 & 2 & 2 & 2 & - \\
\hline 5 & Flooring & 3,4 & & - & 2 & 2 & 2 & 2 & 2 & 2 & 2 & 2 & 2 & 2 & - \\
\hline
\end{tabular}

Solutions of the mathematical model based on the above input values were found by means of LINGO 12.0 Optimization Modeling Software by Lingo Systems Inc. The model was solved for a series of acceptable project duration values, $T$. This way, two nondominated solutions for the time-cost optimization problem were found. With the first solution, project duration was 82 days at a cost of $40400 €$. The other solution scheduled the project to last 69 days, and the cost was $44200 €$. In both these solutions the idle time of crews is 0 . For both solutions, the optimal mode for partition walls was precision ceramic hollow blocks joined by adhesive, and for plastering - gypsum plaster. However, the first non-dominated solution preferred monolithic screeds, whereas the other one - prefabricated ones. Time-location schedules of the non-dominated solutions are presented in figures 1 and 2. 


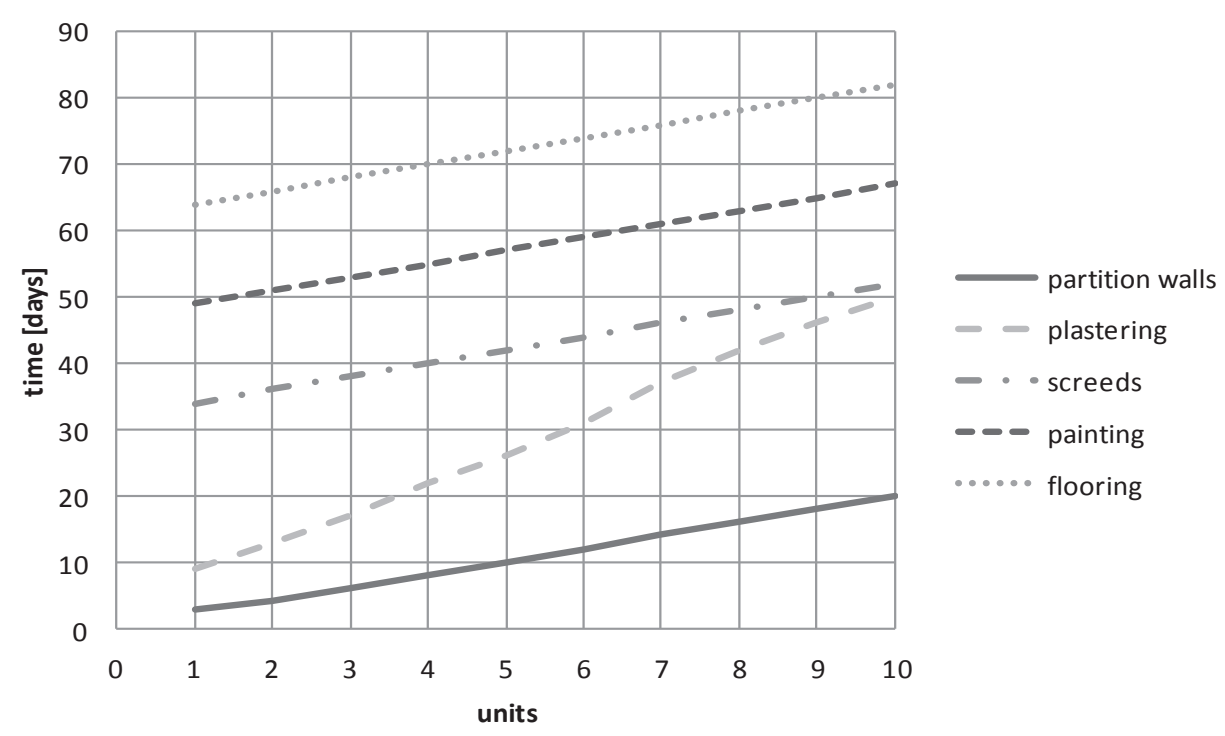

Fig. 1. Project schedule for the solution with project duration of 82 days and project cost $40400 €$

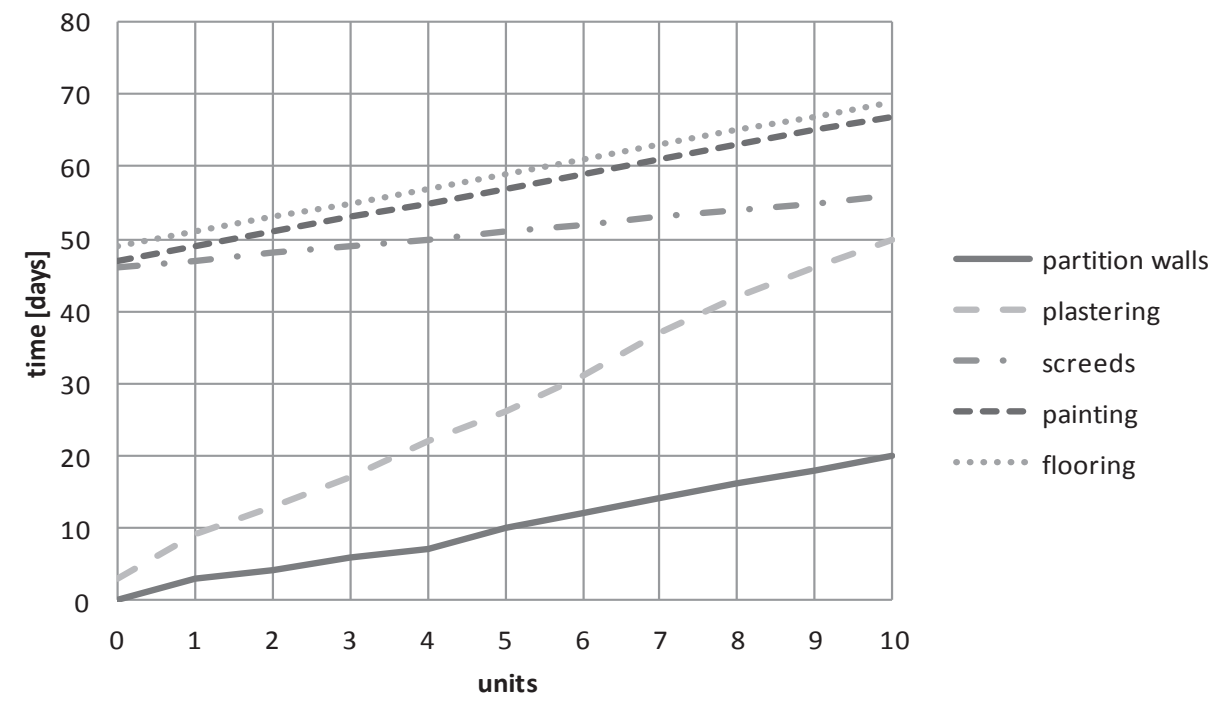

Fig. 2. Project schedule for the solution with project duration of 69 days and project cost $44200 €$

To select the best schedule, one should resort to economics: consider the cost of reduction of project duration, and allow for the decision-makers preferences towards process modes.

\section{Conclusions}

From the practical point, the methods that facilitate considering various options of project execution and their effect on duration and cost are useful. The relationship between time and cost of processes is usually of a discreet character. This study put forward 
a scheduling model for repetitive construction processes that enables choosing optimal processes modes assuring project cost minimization and effective resources utilization.

The approach adopted by the author for planning process times at predefined project duration is aimed at improving efficiency of operations. Striving for continuity of crews' work is important specifically to the contractor. Minimizing idle time reduces cost. The proposed model enables the planner to find solutions that satisfy both the contractor and the client.

To solve the model, the author used a general purpose software. However, it seems reasonable to develop a dedicated application to make the implementation of such models to practical construction problems easier and user-friendly.

\section{Acknowledgment}

This work was financially supported by Ministry of Science and Higher Education within the statutory research number $\mathrm{S} / 63 / 2015$.

\section{References}

1 Alexandros K., Sergios L. Correspondence of activity relationships and critical path between time-location diagrams and CPM. Operational Research 4(3) (2004) 277-290.

2 Ammar M.A. $L O B$ and CPM integrated method for scheduling repetitive project. Journal of Construction Engineering and Management 139(1) (2013) 44-50.

3 El-Kholy A.M. Scheduling repetitive construction projects using fuzzy linear programming. IOSR Journal of Mechanical and Civil Engineering 4(2) (2012) 13-22.

4 Fan S.L., Sun K.S., Wang Y.R. GA optimization model for repetitive projects with soft logic. Automation in Construction 21 (2012) 253-261.

5 Hegazy T., Wassef N. Cost optimization in projects with repetitive nonserial activities. Journal of Construction Engineering and Management 127(3) (2001) 183-191.

6 Hyari K., El-Rayes K. Optimal planning and scheduling for repetitive construction projects. Journal of Management in Engineering 22(1) (2006) 11-19.

7 Ispilandis P.G. Multi-objective linear programming model for scheduling linear repetitive projects. Journal of Construction Engineering and Management 133(6) (2007) 417-424.

8 Kang L.S., Park I.C., Lee B.H. Optimal schedule planning for multiple, repetitive construction process. Journal of Construction Engineering and Management 127(5) (2001) 382-390.

9 Khalied H., Khaled E. Optimal planning and scheduling for repetitive construction projects. Journal of Management in Engineering 22(1) (2006) 11-19.

10 Wang W., Wang X., Ge X., He Y. Resource continuity constraints in repetitive project scheduling. Journal of Information \& Computational Science 10:17 (2013) 5619-5628. 
